\title{
Um olhar sobre a historiografia africana e afro-brasileira
}

\section{A look at African and African-Brazilian historiography}

Luciano Everton Costa Teles*

\section{Resumo}

$\mathrm{O}$ artigo tem como objetivo lançar um olhar sobre a construção de uma nova historiografia sobre a África, destacando o movimento histórico que promoveu o processo de construção desta historiografia e suas características. Visa também resgatar e caracterizar a produção histórica brasileira sobre o afro-brasileiro.

Palavras-chave: história; historiografia africana; historiografia afro-brasileira.

\section{Abstract}

The article aims to cast a glance at the construction of a new historiography about Africa, highlighting the historical movement which promoted this process and the characteristics of this new historiography. It also seeks to recover and characterize the historical production of the African-Brazilian population.

Keywords: history; African historiography; African-Brazilian historiography.

No primeiro semestre de 2011, quando eu atuava como professor substituto da Universidade Federal do Amazonas (UFAM), surgiu uma oportunidade de trabalho no programa federal de formação de professores (Parfor) em Manacapuru. A disciplina era História da África e dos Africanos no Brasil.

No decorrer das aulas algumas questões emergiram e geraram inquietações, sobretudo após discussões estabelecidas com os professores da Educação Básica. Apesar dos esforços realizados nos últimos 30 anos para produzir e difundir estudos relacionados à África e aos afrodescendentes - fruto da institucionalização desses campos e das pesquisas daí resultantes, nacional e internacionalmente - e apesar das obras já publicadas, esses professores reclamaram da ausência de uma sistematização dos pontos centrais da nova perspectiva historiográfica que emergiu num contexto histórico específico, o mundo pós-guerra, em que dois elementos convergiram e proporcionaram

* Centro de Estudos Superiores de Tefé, Universidade do Estado do Amazonas (Cest/UEA). Estrada do Bexiga, 1085, Jerusalém.69470-000 Tefé - AM - Brasil. lcteles@uea.edu.br 
essa renovação nos estudos africanistas, quais sejam: o processo de libertação nacional de regiões da África e as renovações conceituais e metodológicas no campo da História.

Entre as questões propostas, destacam-se estas: "Que elementos históricos concorreram para a emergência de uma nova historiografia africana?”; "Quais são as bases e os elementos que compõem esta nova historiografia?"; "E no Brasil, como se caracterizou a historiografia que tomava o elemento afrodescendente como objeto de estudo?".

Buscando responder a essas questões, buscou-se sistematizar e apresentar uma breve discussão sobre a (des)construção da história da África pelos africanos, destacando o movimento que promoveu esse processo, bem como as características dessa produção. Em seguida, procurou-se resgatar e caracterizar a produção brasileira sobre os afrodescendentes.

\section{A (DES)CONSTRUÇÃO DA HISTORIOGRAFIA DA ÁFRICA PELOS AFRICANOS}

Os primeiros trabalhos sobre a história da África são tão antigos quanto o início da história escrita. Os historiadores do velho mundo mediterrânico e os da civilização islâmica medieval tomaram como quadro de referência o conjunto do mundo conhecido, que compreendia uma considerável porção da África. ${ }^{1}$

No campo da História, os estudos sobre a África remontam a tempos antigos. Tais estudos incorporavam sobretudo o norte da África, e se estenderam até a expansão do Império Otomano (século XVI). Ao longo do tempo, notadamente no decorrer do século XIX, o norte da África continuou sendo um campo de estudos (Fage, 2010, p.2).

Percebe-se que nos momentos de expansionismo militar e econômico, porções do continente africano tornaram-se áreas de influências de determinadas potências europeias - principalmente Inglaterra e França. Essas potências realizaram uma série de estudos nos mais variados campos do conhecimento - História, Geografia, Literatura etc.

Com efeito, uma construção discursiva sobre a África constituiu-se, permeada por interesses políticos e econômicos. Edward Said realizou reflexões acerca desse processo para o Oriente, colocando em relevo os interesses acima 
mencionados bem como as relações de poder que permeavam os discursos sobre o Oriente. Consoante Said, no decorrer do século XIX “o conhecimento político sobre o Oriente era político". ${ }^{2}$

Cabe destacar que foi com a obra de Said intitulada Orientalismo: o Oriente como invenção do Ocidente que a discussão acerca das perspectivas eurocêntricas no campo das ciências sociais, em especial a História, implantou-se no cenário acadêmico internacional.

Nesse sentido, desde tempos antigos é por meio das frentes de expansão econômica e militar europeia que a África foi observada pelos olhos ${ }^{3}$ europeus. Em determinados contextos, como por exemplo, o da expansão marítima e comercial realizada pelos europeus a partir do século XV e, em momento posterior, como no século XIX sob a égide do Imperialismo, os contatos e, consequentemente os discursos e intervenções sobre o continente africano tornaram-se mais intensos.

Considerando o século XIX, não se deve esquecer que ele foi marcado pelo avanço do capitalismo na Ásia e na África. ${ }^{4}$ Nesse sentido, a presença e a exploração dessas áreas necessitavam de justificativas. Essas justificativas foram construídas tendo como base os discursos estabelecidos sobre porções da Ásia e da África. Existia no bojo de alguns discursos uma ideia de 'missão civilizatória':

No século XIX, as crenças científicas, oriundas das concepções do Darwinismo Social e do Determinismo Racial, alocaram os africanos nos últimos degraus da evolução das 'raças' humanas. Infantis, primitivos, tribais, incapazes de aprender ou evoluir, os africanos deveriam receber a benfazeja ajuda europeia, por meio das intervenções imperialistas no continente. ${ }^{5}$

As construções discursivas sobre a África entre os séculos XV-XVII e XIX-XX foram criadas em função dos interesses políticos e econômicos das potências que a tornaram área de influência. À medida que os contatos com esse continente foram acontecendo, produções de obras literárias, jornalísticas e similares foram se constituindo e sendo utilizadas pelos historiadores.

Denominados de 'historiadores modernos', esses estudiosos se ampararam justamente nos documentos construídos graças aos viajantes e comerciantes que se fizeram presentes em regiões da África, incorporando nos seus es- 
tudos muito dos preconceitos que esses grupos acabaram registrando, principalmente a ideia de que a sociedade europeia prevalecia sobre a africana.

Pode ser que, no futuro, haja uma história da África para ser ensinada. No presente, porém, ela não existe; o que existe é a história dos europeus na África. O resto são trevas... e as trevas não constituem tema de história. Compreendam-me bem. Eu não nego que tenham existido homens mesmo em países obscuros e séculos obscuros, nem que eles tenham tido uma vida política e uma cultura interessantes para os sociólogos e os antropólogos; mas creio que a história é essencialmente uma forma de movimento e mesmo de movimento intencional. Não se trata simplesmente de uma fantasmagoria de formas e de costumes em transformação, de batalhas e de conquistas, de dinastias e de usurpações, de estruturas sociais e de desintegração social. ${ }^{6}$

De qualquer maneira, a África era vista como algo menor. Os movimentos e as dinâmicas das etnias que ali estavam presentes eram literalmente encarados como se não tivessem nenhuma influência sobre as regiões da própria África e do mundo.

A escrita da história sobre a África era externa (de fora) e assentada no eurocentrismo. Interessante entender o eurocentrismo como "ideologia e paradigma, cujo cerne é uma estrutura mental de caráter provinciano, fundada na crença da superioridade do modo de vida e do desenvolvimento europeu-ocidental". ${ }^{7}$ Estrutura mental de caráter provinciano pelo fato de o modelo de desenvolvimento econômico e social ser estritamente singular, europeu, o que foi exportado ideologicamente. Segundo o conjunto de ideias exportadas, inevitavelmente todas as sociedades caminhariam para o modelo de desenvolvimento europeu, o que tornou esse modelo um paradigma.

Assim entendido, é hoje perceptível o quanto este eurocentrismo esteve presente nos textos clássicos que fundaram a historiografia moderna no Iluminismo, deturpando a visão dos europeus acerca dos demais povos do mundo. Estes eram vistos, então, na melhor das hipóteses, como crianças a serem educadas pelas luzes da razão.

...

O mesmo olhar pode ser identificado no pensamento social europeu do Novecentos, de forma mais diversificada. Existe uma tendência eurocêntrica recorrente, por exemplo, nas Filosofias da História dos séculos XVIII e XIX, a partir 
de autores clássicos como Voltaire, Vico, Condorcet, Hegel, Marx e Engels. É certo que existe uma heterogeneidade evidente no pensamento de tais autores. Todavia, o que os une - enquanto principais fundadores da Teoria da História - são suas tentativas de, a partir da Filosofia, construir interpretações evolutivas da sociedades humanas, baseadas no progresso da história europeia-ocidental. (Barbosa, 2008, p.47)

Por força disso, aspectos das sociedades e culturas africanas como práticas agrárias, receitas de cozinha, medicamentos da farmacopeia, direitos consuetudinários, organizações políticas, produções artísticas, celebrações religiosas e refinados códigos de etiqueta eram temáticas não cogitadas ${ }^{8}$ ou marginais, vistas pelo contraponto de uma "compreensão econômico-social europeia (o capitalismo); culturalista (modernidade, cultura greco-romana); religiosa (judaico-cristã); racial ('branca'), etc.” (Barbosa, 2008, p.48).

Numa espécie de movimento contrário, um grupo de intelectuais africanos mobilizou esforços no sentido de reescrever a história africana:

A partir de 1947, a Societé Africaine de Culture e sua revista Présence Africaine empenharam-se na promoção de uma história - da África descolonizada. Ao mesmo tempo, uma geração de intelectuais africanos que havia dominado as técnicas europeias de investigação histórica começou a definir seu próprio enfoque em relação ao passado africano e a buscar nele as fontes de uma identidade cultural negada pelo colonialismo. Esses intelectuais refinaram e ampliaram as técnicas da metodologia histórica desembaraçando-a, ao mesmo tempo, de uma série de mitos e preconceitos subjetivos. (Fage, 2010, p.20)

Nessa esteira, a reconstrução da história da África passou a ser almejada. Três elementos se colocaram como pilares para essa reconstrução. O primeiro elemento se materializou num esforço no sentido de corrigir as interpretações anteriores, modificando os julgamentos de valor: "De heróis da civilização em marcha, os desbravadores, governadores das colônias, oficiais do exército, tornam-se cruéis exploradores". ${ }^{9} \mathrm{O}$ segundo elemento esteve ligado a um processo de descolonização da história do período colonial que se deu simultaneamente aos movimentos nacionalistas pela independência:

Sobretudo nos anos 60, os estudiosos começaram a retroceder o tempo, buscando as raízes da resistência e dos movimentos de protesto no início da época colo- 
nial e, mais longe ainda, nas primeiras tentativas de resistência ao jugo europeu. Estes trabalhos sobre os movimentos de resistência e de protesto constituem uma importante contribuição para corrigir os desvios da história colonial... (Curtin, 2010, p.44)

O terceiro e último elemento caracterizou-se numa abordagem diferenciada que emergiu contra a história eurocêntrica e elitista. Ou seja, era fundamental resgatar os movimentos e as dinâmicas próprios das sociedades africanas, considerando os grupos sociais presentes no continente.

Esses três elementos tinham como finalidade a construção de uma nova escrita da história para o continente africano, tarefa levada a cabo por historiadores africanos. Para estes, era essencial resgatar temas e questões antes negligenciados por uma historiografia exógena que não percebia a África como histórica ou que a percebia por meio das ações dos europeus nesse continente ao longo do tempo.

No âmbito deste esforço geral, o papel dos historiadores da África na própria África e fora dela assumia particular importância, provavelmente pelo fato de a história africana ter sido mais negligenciada que a das regiões não europeias equivalentes e porque os mitos racistas a desfiguram ainda mais que a estas últimas. (ibidem, p.40)

Esse processo, como é possível notar na citação, envolveu historiadores 'externos' também. Quando os estudos africanistas começaram a ser introduzidos no mundo acadêmico em países ocidentais entre 1950 e 1960, sobretudo na França, na Inglaterra e nos Estados Unidos, as pesquisas ainda estavam ancoradas em bases eurocêntricas. Porém, aspectos relacionados ao continente africano e as relações estabelecidas historicamente com esse continente foram alvos de reflexão.

Cabe destacar que o continente africano e também aqueles que começaram um processo de formação na área de História dependiam das instituições acadêmicas dos países citados anteriormente. Assim, professores ocidentais atuaram como professores de História nas instituições africanas, assim como as universidades europeias recepcionaram estudantes africanos.

Porém, esse contexto promoveu uma ampliação dos estudos africanos que, junto ao movimento de renovação na oficina de Clio, cuja proposta para 
nortear uma nova escrita da história teve como eixo três pontos básicos - interdisciplinaridade, perspectiva totalizante e história-problema e os movimentos de libertação nacional na África -, passaram a impulsionar os estudos históricos, com a formulação de métodos de investigação e interpretação histórica.

Dessa forma, a História da África passou a ser (re)escrita considerando o africano como sujeito da sua própria história, agindo de forma decisiva nos acontecimentos históricos. Além disso, a História Oral passou a ser utilizada como suporte para construir uma nova interpretação da África, e a interdisciplinaridade tornou-se instrumento para estabelecer um diálogo com outras áreas do conhecimento visando uma compreensão maior de determinados aspectos, sobretudo materiais e culturais. Enfim, estabeleceu-se, entre 1950 e 1980, um processo de (des)construção da história da África pelos profissionais africanos. O maior exemplo desse processo foi a participação de intelectuais estrangeiros, principalmente africanos, num projeto com apoio e financiamento da Unesco que visava produzir uma nova história da África.

A evolução dessa articulação intelectual e política alcançou, então, os organismos permanentes internacionais ainda na década de 60. Amadou-Mahtar M'Bow, eminente intelectual senegalês, assume o cargo de diretor geral da Unesco - Órgão das Nações Unidas para a Ciência e a Cultura. Entre 1965 e 1969 foi gestado sob seu patrocínio um ambicioso projeto: tratava-se de organizar o mais extensa e completamente a historiografia sobre África até o momento, ao mesmo tempo que propiciar aos especialistas as condições de intensificar e aprimorar pesquisas com diversas abordagens, além de estudarem mais ampla e detidamente as relações inter-regionais em África e dessa com outros continentes. O resultado foram oito volumes com cerca de 800 páginas cada. A redação e a publicação das obras ficaram a cargo de um comitê internacional de 39 membros (dois terços de africanos) sob a coordenação geral de Joseph Ki-Zerbo - um professor senegalês. ${ }^{10}$

No Brasil esses volumes foram publicados mediante convênio entre a Unesco e a Editora Ática, nos primeiros anos da década de 1980. Recentemente o governo brasileiro disponibilizou o conjunto na internet, ${ }^{11}$ o que denota um esforço em tornar públicos os estudos sobre a África.

Mais recentemente, a escrita da história sobre a África incorporou estudos ligados "às epidemias, ao cotidiano, às novas tendências da economia e da 
ciência política, da importância do regional, do gênero, da escravidão, da cultura política e das influências da literatura" (Curtin, 2010, p.43). Para além disso,

Estudos sobre o passado remoto ou recente das regiões, do processo de formação da África atual, do entendimento da diversidade de suas culturas e povos, das releituras sobre os contatos com os europeus e sobre os complexos problemas a que submerge hoje o continente foram alvo de uma quantidade avassaladora de investigações. (ibidem, p.41)

As investigações caminharam, portanto, no sentido de "focar a África em sua própria trajetória. As histórias dos reinos e civilizações africanas..." (Oliva, 2003, p.440). Assim, uma nova história da África acabou emergindo, incorporando novas temáticas com base em novas visões e interesses.

Um dos principais debates atuais dessa historiografia refere-se à questão do tráfico de escravos. Numa perspectiva tradicional, eurocêntrica, o tráfico de escravos intensificou-se e consolidou-se a partir da montagem do império marítimo e comercial europeu. Foi estabelecido pela hegemonia do capital mercantil europeu com o objetivo de assegurar e suprir de mão de obra os setores produtivos incentivados pelas metrópoles europeias nas colônias. Nesse ínterim, o tráfico de escravos acabou sendo percebido como um fenômeno externo à África, produzido pelos europeus.

Nesse esquema explicativo, a África só era mencionada à medida das operações ligadas ao tráfico de escravos, identificando, quando muito, as regiões de onde os escravos provinham. A participação e os interesses que levaram o continente africano a estabelecer contato e fornecer escravos para os europeus, por exemplo, não eram questionados. Nem a lógica interna que porventura tenha contribuído para a estruturação da oferta de escravos aos europeus.

Atualmente, os estudos relacionados ao tráfico negreiro não negligenciam a história da África. Nesse sentido, as regiões e os segmentos africanos que estabeleceram contato e produziram escravos para serem oferecidos aos europeus foram questionados, a exemplo da obra de Manolo Florentino intitulada Em Costas Negras: uma história do tráfico de escravos entre a África e o Rio de Janeiro, publicada pela Companhia das Letras em 1997.

Outro ponto de debates no campo da atual historiografia da África refere-se à inclusão dos territórios da diáspora como parte das áreas cobertas pela 
história da África. Na perspectiva eurocêntrica, as relações entre o continente africano e o mundo atlântico, por exemplo, eram consideradas como um acidente geográfico entre o Oriente e o Ocidente. Desse modo, consoante Amailton Magno Azevedo

Os processos de desterramento, desterritorialização e escravidão que provocaram as ondas migratórias da Diáspora foram vistos como um projeto balizado pelo expansionismo do Estado-nação, da economia capitalista e dos desdobramentos da modernidade europeia. Sendo assim, as Áfricas e as Diásporas não são associadas a espaços e vivências portadores de memórias, saberes e fazeres. ${ }^{12}$

Com efeito, construiu-se uma crítica sobre essa ideia acerca dos territórios da Diáspora. Estes passaram a ter papel decisivo "na formação de novas memórias, saberes e fazeres no Mundo Atlântico" (ibidem, p.365). A obra de Luiz Felipe de Alencastro, O trato dos viventes: a formação do Brasil no Atlântico Sul, publicado também pela Companhia das Letras em 2001, constitui exemplo interessante dessa nova perspectiva.

Os dois debates atuais no campo da historiografia africana destacados neste artigo (Tráfico negreiro e Territórios da Diáspora) apenas mencionam o enriquecimento e as possibilidades presentes nesse campo de estudos.

\section{HistóRIA E CULTURA AFRO-BRASILEIRAS}

No Brasil, os temas e discussões ligados às questões afro-brasileiras são alvo de reflexões há mais de um século. Nina Rodrigues se destacou nesses temas, mas o negro foi considerado por ele como degenerado, sem capacidades de aperfeiçoamento moral e social, visto portanto como obstáculo ao desenvolvimento do país. Em sua obra, Os africanos no Brasil, ${ }^{13}$ procurou explicitar esse quadro.

Resultado de pesquisa conduzida por Nina Rodrigues entre africanos remanescentes na Bahia do fim do século XIX, mas só publicada, postumamente, em 1932, o livro tinha objetivos claros: identificar os traços físicos e culturais africanos que haviam se infiltrado na 'raça' brasileira durante os séculos anteriores, resultante da maciça importação de africanos pelo tráfico atlântico e de intensa miscigenação. A reflexão do médico era inspirada pela ideologia racista que atri- 
buía à miscigenação os males e entraves ao desenvolvimento do país, porque a 'civilização' estava associada a uma população de cor branca e hábitos europeus. ${ }^{14}$

Somente na Semana de Arte Moderna, em 1922, surgiu um repensar da nação - a brasilidade -, lançando as bases do mito das três raças como elementos essenciais da formação do Brasil, fato esse explorado pela Revolução de 1930 e pelo Estado Novo. ${ }^{15}$

Esse movimento forçou o universo acadêmico a inquirir sobre o lugar do negro na identidade brasileira. Por força disso realizou-se o I Congresso Afro-Brasileiro (Recife, 1934) e sua segunda edição (Salvador, 1937), com Gilberto Freyre, Édison Carneiro e Manuel Querino. Nesses Congressos o principal objetivo era entender a 'questão negra' para a constituição do 'caráter nacional brasileiro'. ${ }^{16}$ Nesse sentido, Gilberto Freyre ${ }^{17}$ lançou a ideia da 'democracia racial'.

Embora Gilberto Freyre tenha valorizado a presença dos portugueses, indígenas e africanos e suas culturas para a formação do Brasil, minimizou o preconceito racial entre os portugueses. ${ }^{18}$

Outros estudiosos como Arthur Ramos, ${ }^{19}$ Édison Carneiro ${ }^{20}$ e Luiz Viana Filho ${ }^{21}$ se debruçaram sobre temáticas afro-brasileiras, formando até mesmo um Centro de Estudos:

Quando se realizou, em 1959, em Salvador, o $2^{\circ}$ Colóquio de Estudos Luso-Brasileiros, chegou à Bahia o professor George Agostinho da Silva, um português que tinha se autoexilado no Brasil depois de haver sido perseguido pelo governo Salazar. Agostinho propôs ao então reitor da Universidade da Bahia, Edgar Rego dos Santos, a criação de um Centro de Estudos Afro-Orientais. O Centro foi criado e retomaram-se, então, os estudos sobre os negros da Bahia. ${ }^{22}$

Nesse Centro de Estudos, as reflexões sobre o negro intensificaram a ideia de sua importância para o entendimento do processo de construção cultural brasileira.

Por sua vez, Caio Prado Júnior, ${ }^{23}$ Florestan Fernandes ${ }^{24}$ e Octávio Ianni ${ }^{25}$ lançaram bases para a compreensão do negro numa outra perspectiva. Ancorados em aportes marxistas, tenderam a considerar o trabalho compulsório como elemento de um sistema de opressão, o capitalismo comercial. A escra- 
vidão derivava, portanto, do sentido mercantil da colonização, e estava umbilicalmente ligada a ela.

Assim, os africanos teriam sido utilizados estritamente como mão de obra, como força de trabalho. Com efeito, surgia a concepção de que a escravidão reduzia o africano a uma condição de anomia social. ${ }^{26}$ Era a ideia reificadora da escravidão.

Entretanto, a África e as suas relações com o nosso país foram minimamente destacadas. Foi somente com José Honório Rodrigues que a relação entre a África e o Brasil emergiram. ${ }^{27}$ Nas últimas duas décadas esses estudos se avolumaram, sobretudo com relação ao africano no Brasil, colocando-o como sujeito de sua própria história. Nessa linha, cabe destacar a obra de Kátia Mattoso, Ser escravo no Brasil, que, segundo Ronaldo Vainfas,

recolocou a importância do paternalismo como mecanismo de poder senhorial e, por meio disso, negou a quase exclusividade do fator violência como explicação do sistema escravista. Indicou também a importância de se estudar a África, o tráfico, as etnias, os mores, as religiões, para se entender a conformação da cultura negra no Brasil - cultura que muitos chamaram de afro-brasileira. (Vainfas, 1999, p.10)

Ainda na década de 1980, os estudos sobre a história da África para compreender os afro-brasileiros começaram a entrar na cena histórica. Por exemplo, João Reis, em sua obra Rebelião escrava no Brasil, recorreu à história da África para analisar a revolta dos Malês na Bahia, em 1834. Também Manolo Florentino e José Roberto Góes, em A paz das senzalas, recorreram a aspectos históricos ligados ao continente africano para lançar luzes sobre os afro-brasileiros. Enfim, a historiografia mais recente tem buscado considerar a história da África como fundamental para o entendimento do tráfico negreiro, da escravidão e dos territórios da Diáspora, só para citar alguns exemplos. Nesse sentido,

Depois de uma geração de historiadores engajada em desmontar o mito da escravidão benevolente, através de estudos sobre a violência no sistema e sobre a resistência escrava, sobretudo violenta, assumiu o debate uma nova geração preocupada com o cotidiano dos escravos e com a variedade de relações dentro do sistema escravista. A nova perspectiva da escravidão se abre com pesquisa empí- 
rica intensiva em materiais manuscritos antes inexplorados, como inventários post-mortem, processos-crime, ações de liberdade, correspondência policial, além de uma leitura 'a contrapelo' de relatos de viajantes e de documentos oficiais ... A pesquisa revela com riqueza de detalhes o funcionamento das relações no sistema escravista e a vida dos escravos propriamente. Enquanto antes os escravos eram vistos como uma massa uniforme, agora percebe-se uma hierarquia entre escravos, e o entrecruzar de identidades, baseadas em gênero, idade, ocupação (escravos rurais, urbanos, domésticos, artesãos, ganhadores etc.) e origem (africanos de diversas etnias ou nascidos no Brasil). (Mamigonian, 2004, p.35-36)

Com efeito, os estudos sobre a África e a cultura afro-brasileira se adensaram. As relações entre a África e o mundo, em especial o Brasil, foram postas em relevo com o surgimento e avanço de cursos de pós-graduação Lato Sensu e Stricto Sensu sobre a História da África e da Cultura Afro-brasileira, além de centros de estudos, a exemplo do Centro de Estudos Afro-Orientais (Ceao) da Universidade Federal da Bahia (UFBA).

\section{CONSIDERAÇÕES FINAIS}

Observa-se que no decorrer de algumas décadas, uma reconstrução da História da África pelos africanos veio se colocando como atividade primordial, não somente para resgatar o movimento e a dinâmica próprios do continente e das populações africanas, como também para promover um olhar mundial tendo a África como foco.

No âmbito nacional, os estudos africanos foram avançando ao longo do tempo, sobretudo deixando de se assentar em questões biológicas e racistas (como é o caso das obras de Nina Rodrigues), em estudos etnográficos (notadamente nas décadas de 1950 e 1960, no interior do Centro de Estudos Afro-Orientais), na percepção da escravidão e do trabalho escravo como elementos do capitalismo comercial, para focar as relações entre a África e o Brasil e as contribuições dos afrodescendentes na formação cultural brasileira.

Os desafios que se apresentam atualmente requerem uma ampliação e intensificação daquilo que a historiografia internacional e nacional vem sinalizando. O grande desafio que o universo docente brasileiro tem é o de "disse- 
minar, para o conjunto da sua população, num curto espaço de tempo, uma gama de conhecimentos multidisciplinares sobre o mundo africano". ${ }^{28}$

Sabe-se que o povo afrodescendente há séculos vem sofrendo preconceitos no interior de nossa sociedade. Parafraseando Laureano, "somente o conhecimento da história e uma compreensão de sua cultura vão encaminhar a nossa sociedade para o rompimento com práticas preconceituosas e discriminatórias". ${ }^{29}$

\section{NOTAS}

${ }^{1}$ FAGE, J. D. A evolução da historiografia da África. In: UNESCO. História Geral da África, I: Metodologia e pré-história da África. 2.ed. Brasília, 2010. p.1.

${ }^{2}$ SAID, E. W. Orientalismo: o Oriente como invenção do Ocidente. São Paulo: Companhia das Letras, 1990.

${ }^{3}$ Olhos no sentido de observação e percepção da África a partir de uma ideologia e de um discurso tendo como base os parâmetros europeus...

${ }^{4}$ HOBSBAWM, E. A era do capital (1848-1975). 13.ed. São Paulo: Paz e Terra, 2007.

${ }^{5}$ OLIVA, A. R. A História da África nos bancos escolares. Representações e imprecisões na literatura didática. Estudos Afro-Asiáticos, ano 25, n.3, 2003. p.436.

${ }^{6}$ TREVOR-HOPER citado em FAGE, 2010, p.8-9.

${ }^{7}$ BARBOSA, Muryatan Santana. Eurocentrismo, História e História da África. Revista Sankofa, n.1, jun. 2008. p.47.

${ }^{8}$ HAMA, B.; KI-ZERBO, J. A evolução da historiografia da África. In: UNESCO. História Geral da África. I: Metodologia e pré-história da África. 2.ed. Brasília, 2010.

${ }^{9}$ CURTIN, P. D. Tendências recentes das pesquisas históricas africanas e contribuição à história em geral. In: UNESCO. História Geral da África. I: Metodologia e pré-história da África. 2.ed. Brasília, 2010. p.43.

${ }^{10}$ PEREIRA, Amauri Mendes. Por que estudar História da África. Grupo de Estudos Afro-brasileiros e Educação, Rio de Janeiro: Uerj, n.21, s.d. p.7.

${ }^{11}$ Na página do domínio público encontram-se os oito volumes.

${ }^{12}$ AZEVEDO, Amailton Magno. África, Diáspora e o Mundo Atlântico na Modernidade: perspectivas historiográficas. Caderno de Pesquisa Histórica, Uberlândia (MG), v.23, n.2, jul.-dez. 2010. p.363.

${ }^{13}$ RODRIGUES, N. Os africanos no Brasil. São Paulo: Madras, 2008.

${ }^{14}$ MAMIGONIAN, B. G. África no Brasil: mapa de uma área em expansão. Revista de História da Universidade Federal do Rio de Janeiro, Rio de Janeiro, n.9, v.5, 2004. p.34. 
${ }^{15}$ ZAMPARONI, V. Estudos africanos no Brasil: Veredas. Revista de Educação Pública, v.4, n.5, 1995.

${ }^{16}$ LEITE, M. D. O caráter nacional brasileiro: história de uma ideologia. 4.ed. São Paulo: Pioneira, 1983.

${ }^{17}$ FREYRE, G. Casa-grande \& senzala. Rio de Janeiro: Record, 1998.

${ }^{18}$ Cabe destacar que Freire, ao observar aspectos relacionados ao espaço da escravidão doméstica, acabou estendendo esses aspectos ao âmbito do escravismo colonial, dando a ele uma conotação menos dura.

${ }^{19}$ RAMOS, A. O Negro Brasileiro. São Paulo: Cia. Ed. Nacional, 1940.

${ }^{20}$ CARNEIRO, E. Antologia do Negro Brasileiro. Porto Alegre: Globo, 1950.

${ }^{21}$ VIANA FILHO, L. O Negro na Bahia. Rio de Janeiro: J. Olympio, 1946.

${ }^{22}$ Entrevista concedida por Waldir Freitas Oliveira. Estudos Avançados, São Paulo, v.50, n.18, 2004. p.128.

${ }^{23}$ PRADO JÚNIOR, C. Formação do Brasil contemporâneo. São Paulo: Brasiliense, 1945.

${ }^{24}$ FERNANDES, F. A integração do negro na sociedade de classes. v.1. 3.ed. São Paulo: Ática, 1978.

${ }^{25}$ IANNI, O. Raças e classes sociais no Brasil. Rio de Janeiro: Civilização Brasileira, 1966.

${ }^{26}$ Os estudiosos da chamada escola histórico-sociológica paulista (1960-1970) encaminharam seus estudos no sentido de afirmar a completa anomia social a que a escravidão acabava reduzindo o africano. Ver VAINFAS, Ronaldo. Colonização, miscigenação e questão racial: notas sobre equívocos e tabus da historiografia brasileira. Revista Tempo, Universidade Federal Fluminense, n.8, ago. 1999. p.9.

${ }^{27}$ RODRIGUES, J. H. Brasil e África - outro horizonte. Rio de Janeiro: Civilização Brasilei$\mathrm{ra}, 1961$.

${ }^{28}$ WEDDERBURN, Carlos Moore. Novas Bases para o ensino da História da África no Brasil. In: BRASIL. Ministério da Educação. Secretaria de Educação Continuada, Alfabetização e Diversidade. Educação Anti-Racista: caminhos abertos pela Lei Federal 10.639/2003. Brasília, 2005. p.4.

${ }^{29}$ LAUREANO, M. A. O Ensino de História da África. Ciência e Letras, Porto Alegre, n.44, 2008. p.343.

Artigo recebido em 20 de dezembro de 2011. Aprovado em 11 de abril de 2012. 